\begin{tabular}{l} 
JOURNAL Of \\
Physical Activity \\
\& Health \\
\hline
\end{tabular}

\title{
Physical activity status in patients with coronary heart disease: results from the cross-sectional EUROASPIRE surveys
}

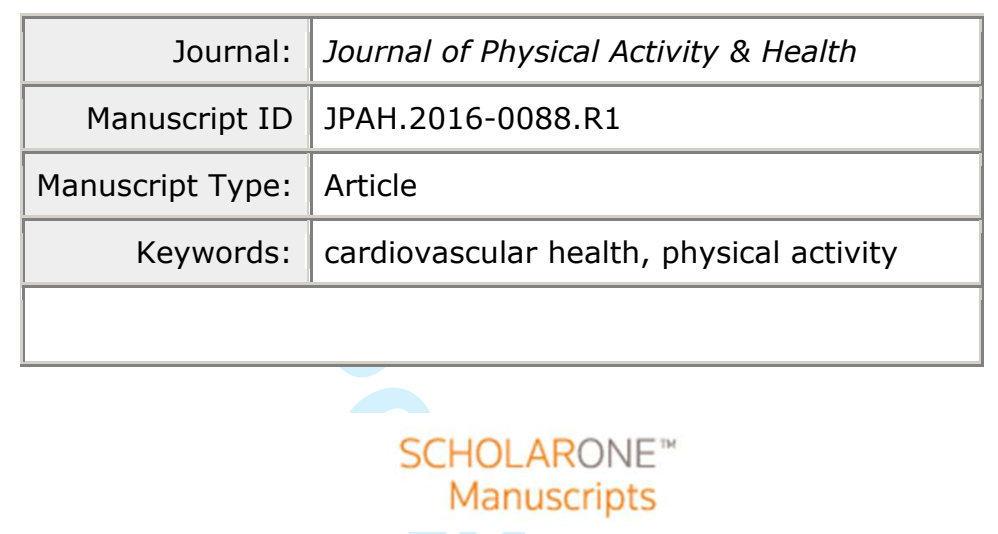


2

3

4

5

6

7

8

9

10

11

12

13

14

15

16

17

\section{TITLE PAGE}

2 Title:

3 "Physical activity status in patients with coronary heart disease: results from the cross-sectional

4 EUROASPIRE surveys".

findings from the cross-sectional EUROASPIRE IV survey

7 Running title: Physical activity in coronary patients

8 Original research

9 Keywords: coronary risk profile; cardiac rehabilitation, preventive cardiology

10 Abstract word count: 200

11 Manuscript word count: 4293

12

13

14

15

16

17

18

19

20

21 
Physical activity in coronary patients

\section{ABSTRACT}

23 Background: The studyaim was to assess the physical activity levels as well as the intention to become 24 physically active in patients with stable coronary heart disease (CHD) with a special focus on the association with their risk profile.

Methods: Analyses are based on the cross-sectional EUROASPIRE IV surveys. Information was available on 8966 patients in EUROASPIRE III and on 7998 coronary patients was available in EUROASPIRE IV. Physical activity level according to patients risk profile and medical management was assessed, the intention to become physically active was investigated and a time trend analysis was performed.

Results: A better cardiovascular risk profile as well as receiving physical activity advice or weight loss advice was associated with better physical activity levels. The physical activity status improved significantly over time, the proportion of patients reporting vigorous physical activity for at least 20

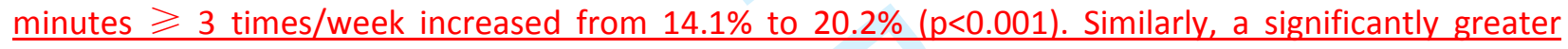
proportion of patients are in the maintenance stage (36.6\% vs. $27.4 \%)$ and a smaller proportion in the precontemplation stage (43.2\% vs. $52.3 \%$.).

Conclusion: Although an increase was seen in the proportion of patients being adequately physical active, physical activity levels remain suboptimal in many CHD patients. Background: The aim of this study was to-assess the physical activity levels as well as the intention to become physically active in patients with stable coronary heart disease (CHD)

Methods: Analyses are based on the EUROASPIRE IV (EUROpean Action on Secondary and Primary 
2

Results: A better cardiovascular risk profile as well as receiving physical activity advice or weight loss advice was associated with better physical activity levels. The physical activity status improved significantly over time, the proportion of patients reporting vigorous physical activity for at least 20 minutes $\geq 3$-times/week increased from $14.1 \%$ to $20.2 \%$ (p<0.001). Similarly, a significantly greater proportion of patients are in the maintenance stage (36.6\% vs. $27.4 \%$ ) and a smaller proportion in the precontemplation stage (13.2\% vs. 52.3\%).

Conclusion: Although an increase was seen in the proportion of patients being adequately physical active, physical activity levels remain suboptimal in many CHD patients. A better risk profile and adequate CHD

(1)

management are associated with higher physical activity levels. 
Physical activity in coronary patients

\section{INTRODUCTION}

65 Even though mortality rates due to cardiovascular disease (CVD) have dropped substantially during the 66 last decades, CVD remains the major cause of premature death in Europe. ${ }^{1}$ Unhealthy lifestyle, such as 67 smoking, physical inactivity and unhealthy eating habits, is strongly related with the development of CVD. 68 According to the WHO, alcohol, tobacco, hypertension, obesity, hypercholesterolemia, unhealthy diet 69 and physical inactivity account for $61 \%$ of all cardiovascular deaths. ${ }^{2}$ Several guidelines on CVD 70 prevention have stressed the importance of healthy lifestyle behaviour. ${ }^{3-5}$ Physical activity is 71 recommended in the prevention and treatment of coronary heart disease (CHD) because of its beneficial

72 effect on blood pressure, lipids, body mass index, HbA1c and inflammatory markers. ${ }^{4,6}$ Furthermore, a 73 direct effect on the vascular wall is found (myocardial oxygen demand; improved myocardial perfusion 74 and antithrombotic effect). ${ }^{4}$ Regular physical activity is associated with a reduced risk for fatal and non75 fatal cardiovascular events, both in healthy persons as well as in CHD patients. A risk reduction between $7630 \%$ and $35 \%$ for developing fatal or non-fatal coronary or cardiovascular disease in the most active 77 versus least active persons has been reported. ${ }^{7}$ Similarly, leisure time physical activity in CHD patients is 78 associated with a decreased all-cause and cardiovascular mortality risk, with sedentary patients having a $7920 \%$ increased long term (15 years) and a $60 \%$ increased short-term (5 years) all-cause mortality risk. ${ }^{8}$

80 The ESC guidelines advise healthy adults to spend 2.5 to 5 hours a week on physical activity of at least 81 moderate intensity or 1 to 2.5 hours a week on physical activity of at least vigorous intensity. Patients 82 with a history of $\mathrm{CHD}$ are advised to perform moderate to vigorous intensity aerobic exercise training at 83 least 3 times a week, 30 min per session. ${ }^{4}$ It is not well-known how the guidelines on physical activity are 84 being followed by CHD patients. Historically, patients have been advised to keep bed rest and limit their 85 mobility after a coronary event. ${ }^{9}$ Although the positive impact of physical activity is well studied over the 86 years, there still might be some misconception among patients. Furthermore, due to the older age of 87 CHD patients, it is not always easy to ensure they are adequately physically active. Hence, the aim of the 
2

88 current study is to assess the physical activity levels as well as the intention to become physically active

89 in patients with stable coronary heart disease using data from the EUROASPIRE (EUROpean Action on

90 Secondary and Primary Prevention through Intervention to Reduce Events) surveys. Finally, a special

91 emphasis was put on the association between the physical activity level and their risk profile and CHD

92 management in order to determine the coronary profile of inactive patients. Furthermore, trends

93 regarding physical activity level in CHD patients were investigated by comparing results from

94 EUROASPIRE III and EUROASPIRE IV.

\section{METHODS}

97 Study population and data collection

The EUROASPIRE surveys are multicentre European cross-sectional studies developed to assess how clinical guidelines on cardiovascular disease prevention are implemented throughout Europe. Analyses were based on data gathered during the recent EUROASPIRE IV survey, performed in (2012-2013), including 7998 patients. ${ }^{10}$ Trend analyses included the results from centres that participated both in the EUROASPIRE III (2006-2007, including 8966 patients) and EUROASPIRE IV survey. Patients eligible for 103 inclusion were men or women, aged $\geq 18$ years and $<80$ years at the time of identification. They were 104 hospitalized for a first or recurrent coronary event, further called the recruiting event, including elective 105 or emergency coronary artery bypass graft surgery (CABG) (with the exclusion of surgery in the context 106 of valve replacement, or when the primary diagnosis is not coronary artery disease); elective or 107 emergency Percutaneous Coronary Intervention (PCI), both stents or other devices; first or recurrent 108 acute myocardial infarction (AMI), ST elevation and non ST elevation myocardial infarction; and acute 109 myocardial ischemia with no evidence of infarction (troponin negative). Patients were retrospectively 110 identified from diagnostic registers, hospital discharge lists or other sources at 78 different hospital 
Physical activity in coronary patients

111 centres in 24 European countries in EUROASPIRE IV: Belgium, Bosnia Herzegovina, Bulgaria, Croatia,

112 Cyprus, Czech Republic, Finland, France, Germany, Greece, Ireland, Latvia, Lithuania, Netherlands,

113 Poland, Romania, Russian Federation, Serbia, Slovenia, Spain, Sweden, Turkey, Ukraine, United Kingdom

114 and from 76 different hospitals in 22 european countries in EUROASPIRE III: Belgium, Bulgaria, Croatia,

115 Cyprus, Czech Republic, Finland, France, Germany, Greece, Hungary, Ireland, Italy, Latvia, Lithuania,

116 Netherlands, Poland, Romania, Russian Federation, Slovenia, Spain, Turkey, United Kingdom. Within

117 each country one or more geographical areas with a defined population were selected and all hospitals

118 serving these populations were identified. A sample of one or more hospitals, or all hospitals, was taken

119 so that any patient presenting within the area had an approximately equal chance of being included.

120 Patients admitted to a hospital outside this geographical area were not included in the sample. ${ }^{10}$ Ethics

121 approval was given by Local Research Ethics Committees. Written informed consent was obtained from

122 each patient. The research was done in accordance with the Declaration of Helsinki.

123 Patients were examined (waist, weight, height, blood pressure, cholesterol, and HbA1c (blood sample

124 analysed centrally) and interviewed (self-reported information on lifestyle, other risk factor

125 management and medication) 6 months to 3 years following the recruiting event. At the time of the

126 interview, a physical examination was performed, assessing height and weight (in light indoor clothes

127 without shoes using a SECA 701/220 [SECA, Hamburg, Germany]), blood pressure (measured at least

128 twice in sitting position with an automatic digital sphygmomanometer [Omron Healthcare, Kyoto,

129 Japan]), breath carbon monoxide using a smokerlyser [Bedfont Scientific, Kent, UK]), and serum

130 cholesterol. Blood analyses were performed in one central laboratory (National Institute for Health and

131 Welfare, Helsinki, Finland). Sociodemographic variables such as age, educational level, and gender were

132 collected. Furthermore, during the interview patients were asked about their current risk factors

133 including medical management, diabetes, and smoking. In addition, patients were asked if they were

134 offered any personal advice by a doctor or other health professional on the following: smoking cessation, 

of the patients was assessed as follows:

137 First, patients were asked to describe their self-perceived physical activity level outside work (getting to 138 and from work, sporting activity and other physical effort during leisure time like gardening or dancing) 139 on the following scale:

$140 \quad-\quad$ no physical activity

$141 \quad-\quad$ light physical activity

142 - vigorous physical activity for 20 minutes once or twice a week

$143 \quad-\quad$ vigorous physical activity for at least 20 minutes $\geq 3$ times a week

144 Vigorous activity was described as activity causing shortness of breath, a rapid heart rate, and sweating.

145 In this study, adequate physical activity outside work was defined as vigorous physical activity for at least

14620 minutes $\geq 3$ times a week according to the guidelines on cardiovascular prevention. ${ }^{4}$

147 Secondly, patients were also asked if they perform regular physical activity of a least 30 minutes duration 148 on average 5 times a week with a yes/no response option (not included in EUROASPIRE III).

149 Finally, patients were also asked about their intention to change their physical activity level using the 150 transtheoretical model of Prochaska et al., differentiating in 5 behavioural stages of change: ${ }^{11}$

151 - I do not exercise regularly and I do not intend to in the next 6 months (precontemplation stage)

152 - I do not exercise regularly, but I intend to in the next 6 months (contemplation stage)

153 - I do not exercise regularly but I intend to in the next 30 days (preparation stage)

$154 \quad-\quad$ I exercise regularly for less than 6 months (action stage)

$155 \quad-\quad$ I exercise regularly for more than 6 months (maintenance stage).

\section{Statistical analyses}

157 Descriptive analyses were used to describe the physical activity level according to patient demographics. 
Physical activity in coronary patients

158 Time trend analysis was based on the comparison of EUROASPIRE IV (2012-2013) with EUROASPIRE III 159 (2006-2007) using multilevel logistic regression analyses adjusted for gender, age, educational level and 160 recruiting event. Only countries that were included in both surveys, 20 in total, were taken into account 161 (Belgium, Bulgaria, Croatia, Cyprus, Czech Republic, Finland, France, Germany, Greece, Ireland, Latvia, 162 Lithuania, Netherlands, Poland, Romania, Russian Federation, Slovenia, Spain, Turkey and United 163 Kingdom). Analyses of the physical activity level according to patients' risk factor profile was also done 164 with multilevel logistic regression adjusted for gender, age, educational level and recruiting event. 165 Analyses were performed using IBM SPSS statistical software (version 21.0). Significance level was set at $166 p<0.05$. The STROBE statement for reporting on observational studies was followed. ${ }^{12}$

RESULTS

A total of 7998 coronary patients were examined and interviewed in EUROASPIRE IV. The mean age was 170 62.5 (9.6) years old, and $24.4 \%$ were females. The question on self-perceived physical activity outside 171 work was completed by 7877 patients (98.5\%) and 7469 patients (93.4\%) completed the question on 172 regular physical activity. Information on the stages of change was available for 7299 patients (91.3\%). 173 Table 1 shows the physical activity level according to patient demographics. Overall, 19.5\% (1536/7877) 174 of patients reported to perform vigorous physical activity for at least 20 minutes three or more times a 175 week (hereafter referred to as adequate physical activity) and 42.9\% (3203/7469) reported to perform 176 regular exercise of at least 30 minutes on average 5 times a week (hereafter referred to as regular 177 exercise). Analyses of the stages of change showed that $5.6 \%$ and $35.6 \%$ of 4 out of 10 patients were in 178 the action or maintenance phase-respectively, $12.3 \%$ and $5.1 \%$ a minority of patients were in the contemplation and preparation phase respectively whereas a majority of patients: $11.5 \%$ was still in 180 thelarge proportion of patients ( 4 out of 10 ) were in the precontemplation phase having no intention to 
181 exercise regularly in the next 6 months. Males, younger patients and higher educated patients were 182 more likely to report higher physical activity.

\section{Physical activity trend EUROASPIRE III vs. EUROASPIRE IV}

184 As shown in table 2 , the physical activity status improved significantly over time $(p<0.05)$ both in males 185 and in females (based on data from countries included in both surveys). The proportion of patients 186 reporting adequate physical activity increased (14.1\% vs. 20.2\%; ( $p<0.001)$. Similar results were shown 187 for the analyses of the stages of change. Compared to the EUROASPIRE III patients, a significantly greater 188 proportion of EUROASPIRE IV patients are in the maintenance stage ( $36.6 \%$ vs. $27.4 \%$ ) and a smaller 189 proportion in the precontemplation stage $(43.2 \%$ vs. $52.3 \%)$.. The proportion of patients in the in190 between phases remained more or less the same. Stratification by gender showed similar results.

191 Physical activity and the association with CVD risk factors

192 A better cardiovascular risk profile was associated with a larger proportion of patients being physically 193 active (see table 3). In males, the proportion of physically active patients was higher in non-smokers 194 compared to smokers $(p<0.001)$, in patients without diabetes compared with patients with diabetes $195(p<0.001)$ and in non-obese versus obese patients $(p<0.001)$. Furthermore, patients being treated with 196 blood pressure lowering medication having a blood pressure on target were more likely to exercise 197 regularly and were more likely to be in the maintenance/action phase. No association between physical 198 activity and raised LDL-cholesterol in patients being treated with lipid lowering medication was seen.

199 Finally, substantial differences in physical activity level were seen between patients with 3 of more risk 200 factors versus patients with less than 3 risk factors (risk factors included: smoking, obesity, elevated LDL201 cholesterol, hypertension and having diabetes or an $\mathrm{HbA} 1 \mathrm{c}>7 \%)(\mathrm{p}<0.001)$.

202 Physical activity and association with advice received 
203 Since the index event, $66.3 \%$ of patients reported to have received advice to increase their physical 204 activity level. Those who reported to have received advice, were more often males (76.8\% vs. $72.7 \%)$, 205 were younger (61.7 years vs. 63.7 years), had a higher education (primary education: $15.8 \%$ vs $20.9 \%$ ), 206 and suffered less often from ischaemia (7.9\% vs. 14.3\%). Receiving physical activity advice was 207 associated with a greater proportion of patients exercising regularly (48.0\% vs. 32.3\%; $\mathrm{p}<0.001)$ and a 208 greater proportion of patients being in the action/maintenance phase (47.2\% vs. $34.4 \%-p<0.001)$ (see 209 table 4). Similarly, patients receiving weight loss advice were also more likely to exercise regularly (38.5\% 210 vs. $35.0 \% ; p<0.001)$ and to be in the action/maintenance phase $(44.1 \%$ vs.34.4\%; $p<0.001)$. Smoking 211 advice and healthy diet advice was not associated with the physical activity level. Furthermore patients 212 who received the advice to follow cardiac rehabilitation, as well as patients who attended at least half of 213 the cardiac rehabilitation sessions were more likely to have a higher physical activity level $(p<0.05)$.

\section{DISCUSSION}

215 The aim of this study was to investigate the physical activity status in patients with a history of CHD, and 216 to assess the association with their risk profile-and their CHD management. Adequate physical activity is 217 associated with a reduced all cause and cardiovascular mortality risk both in healthy persons ${ }^{13-14}$ as well 218 as in CHD patients ${ }^{7,8,15}$. Guidelines on cardiovascular prevention stress the importance of physical activity. 219 CHD patients are advised to perform moderate to vigorous intensity aerobic exercise training at least 3 220 times a week, 30 min per session. ${ }^{4}$ Our analyses have shown that the physical activity level of CHD 221 patients across Europe has increased between 2007 and 2013. A 43\% increase was seen in the 222 proportion of patients performing vigorous physical activity for at least 20 minutes $\geq 3$ times a week. 223 Likewise a $32.5 \%$ increase and a $17.5 \%$ decrease was seen in the proportion of patients being in the 224 maintenance and the precontemplation phase respectively. This trend was seen in both genders and 225 could not be explained by the changes in risk factor profile between both surveys. Part of this 
226 improvement might be caused by the increased advice of health care professionals to participate in a 227 cardiac rehabilitation program (44.8\% in EUROASPIRE III and 50.7\% in EUROASPIRE IV received the advice 228 to participate in a rehabilitation program)..$^{10,16}$ Despite the significant increase in exercise, the physical 229 activity in many CHD patients remains suboptimal with a substantial room for improvement.

230 Based on the large, multicentre international STABILITY (Stabilisation of Atherosclerotic Plaque By 231 Initiation of Darapladib Therapy) study including 15,828 CHD patients from 39 countries, Stewart and 232 colleagues investigated the factors associated with low activity levels in patients with stable CHD. ${ }^{17}$ 233 STABILITY is a large international trial. Our EUROASPIRE IV study results confirmed the STABILITY findings 234 showing a better risk factor profile in physically active CHD patients. Stewart et al. found that a lower 235 education and poorer general health was associated with lower physical activity levels. ${ }^{17}$ In contrast with 236 our findings and the general population findings, ${ }^{2}$ they reported male gender being associated with 237 lower physical activity. These contrasting findings might be associated with the way their physical activity 238 level was questioned. In the EUROASPIRE survey, physical activity questions focus on regular physical 239 activity and vigorous physical activity increasing the breathing rate and causing to break a sweat, 240 whereas in the STABILITY study, the CHD patients have listed all physical activity during the past week, 241 including household chores, which are more often performed by females, especially in that age category 242 ( $\geq 60$ years). The association between the physical activity stage and the risk factors profile was also seen 243 in the general population. ${ }^{18}$

The WHO PREMISE (WHO study on Prevention or Recurrences of Myocardial Infarction and StrokE) study 245 including 10,000 Myocardial infarction and stroke patients from 10 different countries, found that $48.5 \%$ 246 of patients engaged in at least $30 \mathrm{~min}$ of physical activity per day. The main reasons for being 247 insufficiently physically active were: the belief that physical activity has negative effects on health, lack 248 of time, and lack of facilities. They also found a significant relationship between education and physical 
Physical activity in coronary patients

249

250

251

activity levels. ${ }^{19}$ The association with educational level was also reported by the PURE (Prospective Urban

Rural Epidemiology) study. This study, including 7519 patient with a cardiovascular disease showed high

$\underline{\text { levels of work or leisure time related physical activity levels in about one in three patients. }}{ }^{20}$

252 Within EUROASPIRE we have also seen that active patients were more likely to have been advised to 253 increase their physical activity; to lose weight if they were obese; or to follow a cardiac rehabilitation 254 programme. Similar to the STABILITY study, EUROASPIRE patients who attended at least half of the 255 cardiac rehabilitation sessions were more likely to be physically active..$^{17}$

256 Some patients might have contra-indications to perform heavy exercise. CHD patients may suffer from 257 symptoms hampering them to be physically active. Additional analyses (results not shown) on the 258 characteristics of low active patients indicated some relevant findings. Some patients feel that they are 259 bothered by being physically restricted or limited in doing sports or exercise which could explain the low 260 physical activity status. In those patients being regular physically active, $22.8 \%$ of patients reported being 261 limited in their physical activities due to a long standing illness, disability or infirmity, whereas in those 262 not being physically active this proportion rose to $31.0 \%$. Likewise, $23.7 \%$ of regular active patients 263 reported their heart problem has bothered them to walk more than 100 yard at a brisk pace, whereas $26436.5 \%$ felt bothered by this in those not regular active. Furthermore, $15.9 \%$ and $21.0 \%$ of regular active 265 patients versus $28.0 \%$ and $35.9 \%$ in patients not being regular active, was bothered by being physically 266 restricted and being limited in doing sports respectively. Similar findings were reported in the STABILITY 267 study. ${ }^{17}$ Indeed a larger proportion of the physically inactive patients report physical restriction due to 268 their heart disease, however the majority of patients did not suffer from symptoms preventing them to 269 exercise. Furthermore, these data do not report on causality. It might be that lower physical activity 270 results in a poorer overall fitness resulting in more discomfort when walking around or doing exercise.

271 Patients reporting to be bothered by their heart problem might also suffer from anxiety or depression or 
272 insufficient social support resulting in a more negative attitude towards their heart disease. ${ }^{21}$ Previously, 273 a bidirectional association between anxiety or depression and physical activity has been observed in the 274 Whitehall II study, ${ }^{22}$ which might also be the case for the more general self-perceived health status, 275 where low physical activity results in more self-reported health status problems, and low health status 276 results in lower physical activity levels. Furthermore, it can be assumed that patients who are not 277 compliant in following the physical activity recommendations, will be more likely to have a lower 278 medication compliance or adherence resulting in a worse risk factor profile.

279 There are some limitations to this study. The most important one being the self-reported nature of the 280 physical activity outcomes resulting in recall bias. Individuals have a tendency to over report on their 281 healthy lifestyle activities. ${ }^{18}$ Furthermore, low levels of recall might result in underreporting of the 282 variable "advice received since their coronary event". Also, motivated patient with higher levels of 283 physical activity might me more aware of the advice they received since their recruiting event. Hence the 284 results, especially regarding the association between physical activity and advice received should be 285 interpreted with caution. However, as the association was only seen with physical activity advice and 286 weight advice and not with smoking advice and healthy diet advice, the findings suggest that physical 287 activity advice might result in better activity levels. Furthermore, although a great effort was done in 288 order to standardize data collection, by trained research personnel using standardized questionnaires and measuring methods, interpersonal and intercultural differences between study nurses from different countries and centres could potentially have an influence on the results.

CONCLUSION

292 In conclusion, physical activity levels in CHD patients have increased but there is still ample room for 293 improvement. A promising time trend in the stages of change was observed with more patients being 294 located in later stages of the transtheoretical model of behavioural stages of change. Nonetheless, a 
Physical activity in coronary patients

295 substantial proportion of patients has no intention to become physically active. Patients who received

296 advice on how to increase their physical activity level were more likely to be physically active. Patients

297 who were advised to follow cardiac rehabilitation and patients who attended at least half of the

298 rehabilitation sessions had also a better physical activity level. Furthermore, physically inactive patients

299 are also more likely to score worse on risk factors such as smoking cessation, BMI, hypertension and LDL-

300 cholesterol.

301

302

303

304

305

306

307

308

309

310

311

312

313

Human Kinetics, 1607 N Market St, Champaign, IL 61825 


\section{COMPETING INTEREST}

315 The authors report no competing interest.

\section{ACKNOWLEDGEMENT}

317 The authors thank the administrative staff, physicians, nurses, and other personnel at the hospitals in 318 which the study was carried out, and all the patients who participated in the EUROASPIRE studies. The 319 EUROASPIRE IV survey was carried out under the auspices of the European Society of Cardiology, 320 EURObservational Research Programme.

\section{FUNDING SOURCES}

322 Unrestricted educational grants to the European Society of Cardiology were obtained from Amgen, 323 AstraZeneca, Bristol-Myers Squibb and AstraZeneca, F. Hoffman-La Roche, GlaxoSmithKline, and Merck 324 Sharp \& Dohme. The sponsors of the EUROASPIRE surveys had no role in the design, data collection, data 325 analysis, data interpretation, decision to publish, or writing the manuscript. Delphine De Smedt is financially 326 supported by the Research Foundation Flanders. 
Physical activity in coronary patients

334

335

336

337

338

339

340

341

342

343

344

345

346

347

348

349

350

351

352

353

354

355

356

357

\section{REFERENCES}

1. Nichols M, Townsend N, Scarborough P, Rayner M. Cardiovascular disease in Europe 2014: epidemiological update. Eur Heart J. 2014; 35(42):2950-2959.

2. World Health Organization. Global health risksmortality and burden of disease attributable to selected major risks. Geneva: World Health Organization; 2009. http://www.who.int/healthinfo/global_burden_disease/GlobalHealthRisks_report_full.pdf Accessed January 14, 2016.

3. Eckel RH, Jakicic JM, Ard JD, de Jesus JM, Houston MN, Hubbard VS, Lee IM, Lichtenstein AH, Loria CM, Millen BE, Nonas CA, Sacks FM, Smith SC, Jr., Svetkey LP, Wadden TA, Yanovski SZ. 2013 AHA/ACC guideline on lifestyle management to reduce cardiovascular risk: a report of the American College of Cardiology/American Heart Association Task Force on Practice Guidelines. J Am Coll Cardio.l 2014; 63(25 Pt B):2960-2984.

4. Perk J, De Backer G, Gohlke H, Graham I, Reiner Z, Verschuren M, Albus C, Benlian P, Boysen G, Cifkova R, Deaton C, Ebrahim S, Fisher M, Germano G, Hobbs R, Hoes A, Karadeniz S, Mezzani A, Prescott E, Ryden L, Scherer M, Syvanne M, Scholte Op Reimer WJ, Vrints C, Wood D, Zamorano JL, Zannad F. European Guidelines on cardiovascular disease prevention in clinical practice (version 2012). The Fifth Joint Task Force of the European Society of Cardiology and Other Societies on Cardiovascular Disease Prevention in Clinical Practice (constituted by representatives of nine societies and by invited experts). Eur Heart J. 2012 ;33(13):1635-1701.

5. Smith SC, Benjamin EJ, Bonow RO, Braun LT, Creager MA, Franklin BA, Gibbons RJ, Grundy SM, Hiratzka LF, Jones DW, Lloyd-Jones DM, Minissian M, Mosca L, Peterson ED, Sacco RL, Spertus J, Stein JH, Taubert KA. AHA/ACCF secondary prevention and risk reduction therapy for patients with coronary and other atherosclerotic vascular disease: 2011 update: a guideline from the American Heart Association and American College of Cardiology Foundation endorsed by the 


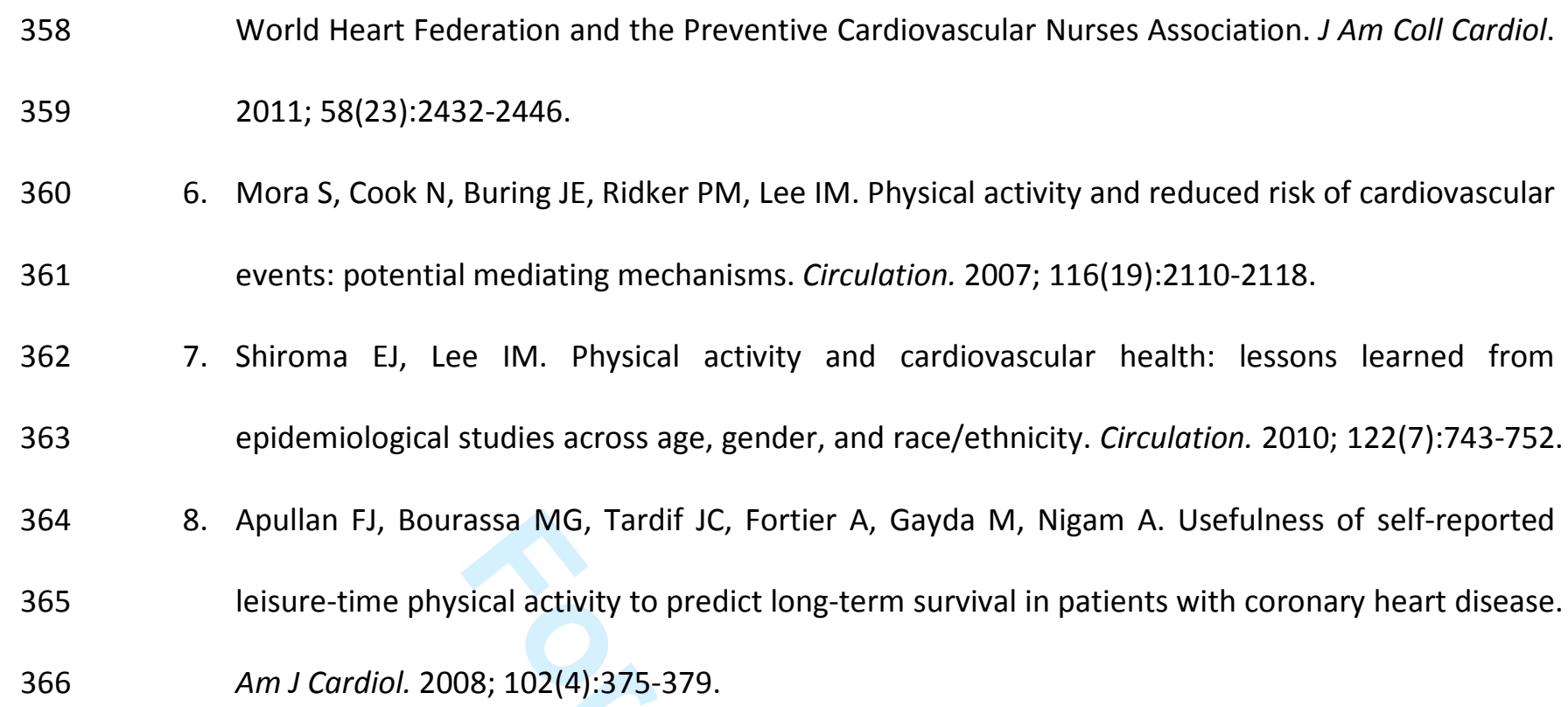


380 13. Nocon M, Hiemann T, Muller-Riemenschneider F, Thalau F, Roll S, Willich SN. Association of physical activity with all-cause and cardiovascular mortality: a systematic review and metaanalysis. Eur J Cardiovasc Prev Rehabil. 2008; 15(3):239-246.

14. Samitz G, Egger M, Zwahlen M. Domains of physical activity and all-cause mortality: systematic review and dose-response meta-analysis of cohort studies. Int J Epidemiol. 2011; 40(5):13821400.

386 15. Heran BS, Chen JM, Ebrahim S, Moxham T, Oldridge N, Rees K, Thompson DR, Taylor RS. Exercise-based cardiac rehabilitation for coronary heart disease. Cochrane Database Syst Rev. 2011; (7):CD001800.

16. Stewart R, Held C, Brown R, Vedin O, Hagstrom E, Lonn E, Armstrong P, Granger CB, Hochman J,

Davies R, Soffer J, Wallentin L, White H. Physical activity in patients with stable coronary heart disease: an international perspective. Eur Heart J. 2013; 34(42):3286-3293.

18. Grossschadl F, Titze S, Burkert N, Stronegger WJ. Moderate- and vigorous-intensity exercise behaviour according to the Transtheoretical Model: associations with smoking and BMI among Austrian adults. Wien Klin Wochenschr. 2013; 125(9-10):270-278.

19. Mendis S, Abegunde D, Yusuf S, Ebrahim S, Shaper G, Ghannem H, Shengelia B. WHO study on

Prevention of REcurrences of Myocardial Infarction and StrokE (WHO-PREMISE). Bull World Health Organ. 2005; 83(11):820-829.

20. Teo K, Lear S, Islam S, Mony P, Dehghan M, Li W, Rosengren A, Lopez-Jaramillo P, Diaz R, Oliveira G, Miskan M, Rangarajan S, Iqbal R, llow R, Puone T, Bahonar A, Gulec S, Darwish EA, Lanas F, Vijaykumar K, Rahman O, Chifamba J, Hou Y, Li N, Yusuf S. Prevalence of a healthy lifestyle among individuals with cardiovascular disease in high-, middle- and low-income countries: The 
1

2

3

4

5

6

7

8

9

10

11

12

13

14

15

16

17

18

19

20

21

22

23

24

25

26

27

28

29

30

31

32

33

34

35

36

37

38

39

40

41

42

43

44

45

46

47

48

49

50

51

52

53

54

55

56

57

58

59

60
Physical activity in coronary patients

403 21. Ronda G, Van AP, Brug J. Stages of change, psychological factors and awareness of physical 404 activity levels in The Netherlands. Health Promot Int. 2001; 16(4):305-314.

405 22. Azevedo Da SM, Singh-Manoux A, Brunner EJ, Kaffashian S, Shipley MJ, Kivimaki M, Nabi H. 406 Bidirectional association between physical activity and symptoms of anxiety and depression: the $407 \quad$ Whitehall II study. Eur J Epidemiol. 2012; 27(7):537-546.

409

410 
Table 1: Physical activity status according to patient demographics

\begin{tabular}{|c|c|c|c|c|c|c|c|}
\hline & Adequate physical & Regular exercise & & & Stages of change & & \\
\hline & activity & & Precontemplation & Contemplation & Preparation & Action & Maintenance \\
\hline All & $19.5 \%(1536 / 7877)$ & $42.9 \%(3203 / 7469)$ & $41.5 \%(3028 / 7299)$ & $12.3 \%(897 / 7299)$ & $5.1 \%(369 / 7299)$ & $5.6 \%(406 / 7299)$ & $35.6 \%(2599 / 7299)$ \\
\hline Gender & & & & & & & \\
\hline Male & $21.6 \%(1287 / 5967)$ & $44.7 \%(2532 / 5665)$ & $39.3 \%(2180 / 5546)$ & $12.5 \%(691 / 5546)$ & $5.4 \%(298 / 5546)$ & $5.8 \%(323 / 5546)$ & $37 \%(2054 / 5546)$ \\
\hline Female & $13 \%(249 / 1910)$ & $37.2 \%(671 / 1804)$ & $48.4 \%(848 / 1753)$ & $11.8 \%(206 / 1753)$ & $4.1 \%(71 / 1753)$ & $4.7 \%(83 / 1753)$ & $31.1 \%(545 / 1753)$ \\
\hline & $P<0.001$ & $P<0.001$ & & & $P<0.001$ & & \\
\hline Age & & & & & & & \\
\hline$<60$ years & $24.1 \%(619 / 2564)$ & $48 \%(1165 / 2426)$ & $33.4 \%(798 / 2386)$ & $6.9 \%(164 / 2386)$ & $16.8 \%(401 / 2386)$ & $8.3 \%(198 / 2386)$ & $34.6 \%(825 / 2386)$ \\
\hline $60-69$ years & $19.8 \%(581 / 2937)$ & $43.8 \%(1226 / 2801)$ & $40 \%(1087 / 2719)$ & $4.6 \%(126 / 2719)$ & $11.9 \%(324 / 2719)$ & $4.9 \%(133 / 2719)$ & $38.6 \%(1049 / 2719)$ \\
\hline$\geq 70$ years & $14.1 \%(336 / 2376)$ & $36.2 \%(812 / 2242)$ & $52.1 \%(1143 / 2194)$ & $3.6 \%(79 / 2194)$ & $7.8 \%(172 / 2194)$ & $3.4 \%(75 / 2194)$ & $33 \%(725 / 2194)$ \\
\hline & $P<0.001$ & $P<0.001$ & & & $P<0.001$ & & \\
\hline Recruiting dia & nosis & & & & & & \\
\hline CABG & $20 \%(203 / 1015)$ & $43.6 \%(423 / 970)$ & $42.8 \%(411 / 960)$ & $11.6 \%(111 / 960)$ & $3.3 \%(32 / 960)$ & $4.6 \%(44 / 960)$ & $37.7 \%(362 / 960)$ \\
\hline $\mathrm{PCl}$ & $20.2 \%(862 / 4260)$ & $43.9 \%(1792 / 4084)$ & $41.9 \%(1682 / 4016)$ & $11.8 \%(472 / 4016)$ & $5.1 \%(203 / 4016)$ & $6.1 \%(245 / 4016)$ & $35.2 \%(1414 / 4016)$ \\
\hline AMI & 19\%(340/1787) & $44.3 \%(728 / 1644)$ & $38.5 \%(621 / 1613)$ & $13.1 \%(212 / 1613)$ & $6.4 \%(104 / 1613)$ & $6.3 \%(101 / 1613)$ & $35.6 \%(575 / 1613)$ \\
\hline
\end{tabular}




\section{Page 21 of 26}

Journal of Physical Activity and Health

1

2

3

$16.1 \%(131 / 815)$

$33.7 \%(260 / 771)$

$42.8 \%(411 / 960)$

$P=0.017$

$P=0.185$

Educational level

Primary

$14.6 \%(200 / 1368)$

$40.3 \%(524 / 1301)$

$44.5 \%(554 / 1244)$

$12.9 \%(160 / 1244) \quad 3.5 \%(44 / 1244)$

$4.9 \%(61 / 1244)$

$34.2 \%(425 / 1244)$

Secondary

$19.8 \%(930 / 4707)$

$42 \%(1862 / 4434)$

$42.8 \%(1856 / 4340)$

$11.7 \%(508 / 4340)$

$5.3 \%(228 / 4340)$

$5.5 \%(238 / 4340)$

$34.8 \%(1510 / 4340)$

High

$22.5 \%(393 / 1748)$

$47.3 \%(793 / 1676)$

$35.8 \%(596 / 1663)$

$13.5 \%(225 / 1663) \quad 5.7 \%(95 / 1663)$

$6.2 \%(103 / 1663)$

$38.7 \%(644 / 1663)$
$\mathrm{P}<0.001$

$\mathrm{P}<0.001$

Multilevel analyses accounting for country differences

\section{$P<0.001$}


Table 2: Time trends

\begin{tabular}{|c|c|c|c|c|c|c|}
\hline & Adequate physical & & & Stages of change & & \\
\hline & activity & Precontemplation & contemplation & preparation & Action & Maintenance \\
\hline All & & & & & & \\
\hline EAIII & $14.1 \%(1099 / 7788)$ & $52.3 \%(3826 / 7313)$ & $10.9 \%(800 / 7313)$ & $4.6 \%(340 / 7313)$ & $4.7 \%(345 / 7313)$ & $27.4 \%(2002 / 7313)$ \\
\hline EAIV & $20.2 \%(1279 / 6331)$ & $43.2 \%(2548 / 5901)$ & $11.7 \%(691 / 5601)$ & $4.6 \%(269 / 5601)$ & $4.3 \%(251 / 5901)$ & $36.3 \%(2142 / 5901)$ \\
\hline & $P<0.001$ & & & $P<0.001$ & & \\
\hline Men & & & & & & \\
\hline EAIII & $15.6 \%(914 / 5865)$ & $49.2 \%(2722 / 5534)$ & $11.3 \%(623 / / 5534)$ & $4.8 \%(268 / 5534)$ & $5.0 \%(279 / 5534)$ & $29.7 \%(1642 / 5534)$ \\
\hline EAIV & $22.3 \%(1074 / 4814)$ & $41.1 \%(1851 / 4507)$ & $11.9 \%(536 / 4507)$ & $4.8 \%(216 / 4507)$ & $4.6 \%(207 / 4507)$ & $37.7 \%(1697 / 4507)$ \\
\hline & $P<0.001$ & & & $P<0.001$ & & \\
\hline Wom & & & & & & \\
\hline EAIII & $9.5 \%(185 / 1923)$ & $62.1 \%(1104 / 1779)$ & $9.9 \%(177 / 1779)$ & $4.0 \%(72 / 1779)$ & $3.7 \%(66 / 1779)$ & $20.2 \%(360 / 1779)$ \\
\hline EAIV & $13.5 \%(205 / 1517)$ & $50.0 \%(697 / 1394)$ & $11.1 \%(155 / 1394)$ & $3.8 \%(53 / 1394)$ & $3.2 \%(44 / 1394)$ & $31.9 \%(445 / 1394)$ \\
\hline & $P=0.006$ & & & $P<0.001$ & & \\
\hline
\end{tabular}

Only centres participating in both surveys are included in the analyses (20 countries)

p-value adjusted for gender, age, recruiting diagnosis, educational level 
Table 3: Physical activity and the association with the CVD risk factor profile

\begin{tabular}{|c|c|c|c|c|}
\hline & & Adequate physical activity & Regular exercise & Action/Maintenance \\
\hline \multirow[t]{3}{*}{ Hypertension $^{a}$} & No & $38 \%(1112 / 2930)$ & $44.9 \%(1815 / 4040)$ & $42.8 \%(1686 / 3941)$ \\
\hline & Yes & $17.4 \%(555 / 3195)$ & $39.3 \%(1175 / 2990)$ & $38 \%(1112 / 2930)$ \\
\hline & & $P=0.420$ & $P=0.001$ & $P=0.010$ \\
\hline \multirow[t]{3}{*}{ Raised LDL-cholesterol $^{b}$} & No & $20.2 \%(263 / 1302)$ & $45.2 \%(566 / 1253)$ & $42 \%(516 / 1228)$ \\
\hline & Yes & $20 \%(970 / 4847)$ & $41.7 \%(1921 / 4602)$ & $41.4 \%(1857 / 4490)$ \\
\hline & & $P=0.278$ & $P=0.375$ & $P=0.207$ \\
\hline \multirow[t]{3}{*}{ Smoking } & No & $20.2 \%(1334 / 6619)$ & $43.9 \%(2772 / 6308)$ & $42.8 \%(2641 / 6171)$ \\
\hline & Yes & $16.1 \%(202 / 1258)$ & $37.1 \%(431 / 1161)$ & $32.3 \%(364 / 1128)$ \\
\hline & & $P<0.001$ & $P<0.001$ & $P<0.001$ \\
\hline \multirow[t]{3}{*}{ Diabetes } & No & $21.6 \%(1239 / 5736)$ & $46.1 \%(2505 / 5435)$ & $44.2 \%(2363 / 5352)$ \\
\hline & Yes & $13.8 \%(291 / 2104)$ & $34.3 \%(686 / 2000)$ & $32.8 \%(629 / 1915)$ \\
\hline & & $P<0.001$ & $P<0.001$ & $P<0.001$ \\
\hline \multirow[t]{3}{*}{ Obesity ${ }^{c}$} & No & $21.8 \%(1068 / 4893)$ & $46.2 \%(2154 / 4660)$ & $45 \%(2052 / 4563)$ \\
\hline & Yes & $15.7 \%(464 / 2951)$ & $37.5 \%(1041 / 2777)$ & $35 \%(948 / 2705)$ \\
\hline & & $P<0.001$ & $P<0.001$ & $P<0.001$ \\
\hline
\end{tabular}


$<3$

$46.3 \%(2133 / 4603)$

$33 \%(687 / 2083)$ \\ $P<0.001$}

Physical activity in coronary patients

\footnotetext{
${ }^{a}$ Blood pressure $>140 / 90$ (140/80 in patients with diabetes) in patients on Blood pressure lowering medication; ${ }^{b}$ LDL-cholesterol $\geq 1.8 \mathrm{mmol} / \mathrm{L}$

in patients on lipid lowering medication; ${ }^{\mathrm{C}} \mathrm{BMI}>30 \mathrm{~kg} / \mathrm{m}^{2} ;{ }^{\mathrm{d}}$ risk factors included are smoking, obesity, blood pressure $>140 / 90(140 / 80$ in patients with diabetes), LDL-cholesterol $\geq 1.8 \mathrm{mmol} / \mathrm{L}$, and having diabetes or an $\mathrm{HbA} 1 \mathrm{c}>7 \%$.

p-value adjusted for gender, age, recruiting diagnosis, educational level
} 
Table 4: Lifestyle advice received (advice since index event, versus never advice received)

\begin{tabular}{|c|c|c|c|c|}
\hline & & Adequate physical activity & Regular exercise & Action/Maintenance \\
\hline \multicolumn{5}{|c|}{ Lifestyle advice received (advice since index event, versus never advice received) } \\
\hline \multirow[t]{3}{*}{ Smoking advice if smoking at hospitalisation } & Yes & $18.9 \%(358 / 1893)$ & $42.1 \%(757 / 1796)$ & $42.9 \%(112 / 261)$ \\
\hline & No & $19 \%(55 / 289)$ & $41 \%(114 / 278)$ & $38.1 \%(666 / 1750)$ \\
\hline & & $P=0.900$ & $P=0.325$ & $P=0.525$ \\
\hline \multirow[t]{3}{*}{ Healthy diet advice } & Yes & $19.4 \%(1246 / 6439)$ & $44 \%(2670 / 6069)$ & $41.4 \%(2456 / 5939)$ \\
\hline & No & $19.8 \%(144 / 727)$ & $41.6 \%(294 / 707)$ & $41.7 \%(283 / 678)$ \\
\hline & & $P=0.755$ & $P=0.165$ & $P=0.388$ \\
\hline \multirow[t]{3}{*}{ Weight loss advice if obese } & Yes & $15.5 \%(389 / 2502)$ & $38.5 \%(902 / 2342)$ & $44.1 \%(2110 / 4787)$ \\
\hline & No & $15.3 \%(31 / 202)$ & $35 \%(69 / 197)$ & $34.4 \%(668 / 1944)$ \\
\hline & & $P=0.381$ & $P<0.001$ & $P<0.001$ \\
\hline \multirow[t]{3}{*}{ Physical activity advice } & Yes & $20.9 \%(1026 / 4910)$ & $48 \%(2233 / 4652)$ & $47.2 \%(2184 / 4625)$ \\
\hline & No & $16.4 \%(405 / 2473)$ & $32.3 \%(762 / 2357)$ & $28 \%(623 / 2228)$ \\
\hline & & $P=0.240$ & $P<0.001$ & $P<0.001$ \\
\hline \multirow[t]{2}{*}{ Cardiac rehabilitation advised } & Yes & $20.9 \%(826 / 3956)$ & $47.7 \%(1772 / 3718)$ & $47.4 \%(1770 / 3732)$ \\
\hline & No & $18 \%(691 / 3836)$ & $38.2 \%(1406 / 3676)$ & $34.6 \%(1210 / 3502)$ \\
\hline
\end{tabular}




$\begin{array}{llllr} & & \mathbf{P}<0.001 & \mathbf{P}=\mathbf{0 . 0 0 1} & \mathbf{P}<0.001 \\ \text { Cardiac rehabilitation attended } & \text { Yes } & 21.8 \%(702 / 3221) & \text { 49.5\%(1492/3016) } & 41.7 \%(282 / 676) \\ & \text { No } & 16.9 \%(124 / 735) & 39.9 \%(280 / 702) & 48.7 \%(1488 / 3056) \\ & & \mathbf{P}=\mathbf{0 . 0 1 5} & \mathbf{P}<0.001 & \mathbf{P}<0.001\end{array}$

p-value adjusted for gender, age, recruiting diagnosis, educational level 